\title{
METODE SIMPLE ADDITIVE WEIGHTING DALAM PEMILIHAN KARYAWAN BERPRESTASI PADA PT. KERETA COMMUTER INDONESIA STASIUN RAWA BUNTU
}

\author{
Yuliantika Siswanti Utami ${ }^{1}$, Kresna Ramanda ${ }^{2}$ \\ ${ }^{1}$ Sistem Informasi, Sekolah Tinggi Manajemen Informatika dan Komputer Nusa \\ Mandiri \\ ${ }^{2}$ Teknik Informatika, Sekolah Tinggi Manajemen Informatika dan Komputer Nusa \\ Mandiri \\ Jl. Damai No. 8 Warung Jati Barat (Margasatwa) Jakarta Selatan \\ Email: ${ }^{1}$ yulistami@gmail.com, ${ }^{2}$ kresna.kra@ nusamandiri.ac.id
}

\begin{abstract}
Rawa Buntu Indonesia Commuter Train Station has its own qualifications in selecting employees, as well as in determining employees who excel. This study aims to give awards to employees who excel. Through this award every employee is expected to be motivated to become better and improve quality. The problem faced is the difficulty in determining who is chosen to be an outstanding employee with subjective criteria. To overcome this problem, a decision support system is designed for the selection of outstanding employees using the SAW Method. By using 5 different variables, namely Integrity, Cooperation, Communication, Quality of Work and Work Discipline.By applying the Simple Additive Weighting method, the process of selecting employee performance is more efficient so that the station can make decisions more quickly for employees who excel. Decision making system using the Simple Additive Weighting method has helped the station in determining the selection of employee performance.
\end{abstract}

Keyword : decision support, employees, simmple additive weighting

\section{PENDAHULUAN}

Pada perusahaan, salah satu elemen yang sangat penting adalah Sumber Daya Manusia (SDM). Pengolahan Sumber Daya Manusia sangat memperngaruhi aspek-aspek penentu keberhasilan kerja dan mencapai target dari perusahaan tersebut. Karena jika Sumber Daya Manusia (SDM) dapat diorganisir dengan baik, maka diharapkan perusahaan dapat menjalankan semua proses usahanya dengan baik. "Disiplin kerja yang baik dapat memberikan kontribusi dalam pelaksanaan beban kerja para karyawannya agar dapat terealisasi dengan baik. Maka dari itu para karyawan diharapkan harus memiliki jiwa disiplin yang tinggi didalam lingkungan kerja agar bisa mendapatkan 
prestasi kerja yang lebih tinggi juga nantinya", (Hi Lawu, dkk, 2019). PT. Kereta Commuter Indonesia merupakan perusahaan yang bergerak di bidang bisnis sebagai penyedia layanan jasa. Dalam melaksanakan operasional perusahaan, PT. Kereta Commuter Indonesia memberikan penghargaan kepada karyawan dengan memilih karyawan berprestasi setiap tahunnya. "Hal ini dimaksudkan untuk meningkatkan semangat karyawan dalam bekerja dan senantiasa menjalankan usaha dengan memenuhi komitmen, memberikan kepastian dan menjamin kepuasan bagi klien dan mitra usaha",(Ilham dan Bakhri, 2017). "Karyawan merupakan faktor pendukung dalam sebuah perusahaan, karena dengan adanya karyawan yang memiliki standar kualifikasi perusahaan maka produktivitas perusahaan pasti tetap terjaga dan semakin meningkat. Untuk memperoleh informasi yang cepat dan akurat prestasi karyawan yang tepat memenuhi kriteria yang diharapkan, dibutuhkan suatu sistem pendukung keputusan pemilihan karyawan berprestasi",(Safitri, dkk, 2017). Menurut (Agustini dan Ariska, 2019), "Penilaian kinerja terhadap suatu pekerjaan dalam sebuah instansi atau perusahaan merupakan suatu tahap evaluasi kerja untuk mengetahui tolak ukur dalam menentukan kualitas serta pencapaian masing-masing karyawannya".

Untuk menentukan karyawan berprestasi biasanya hanya dilakukan secara manual. Oleh karena itu pada penelitian ini akan diangkat kasus yaitu mencari karyawan berprestasi berdasarkan kriteria-kriteria yang telah ditentukan dengan menggunakan metode Simple Additive Weighting (SAW) untuk melakukan perhitungan pada kasus pemilihan karyawan berprestasi. "Metode Simple Additive Weighting $(S A W)$ adalah mencari penjumlahan terbobot dari rating kinerja pada setiap alternatif pada semua atribut. Metode Simple Additive Weighting (SAW) membutuhkan proses normalisasi matriks keputusan (X) ke suatu skala yang didapat diperbandingkan dengan semua rating alternatif yang ada", (Chyntiari dan Prihatin, 2018). "Keunggulan dari metode Simple Additive Weighting dibandingan dengan metode sistem keputusan yang lain terletak pada kemampuannya dalam melakukan penelitian secara lebih tepat karena didasarkan pada nilai kriteria dan bobot tingkat kepentingan yang dibutuhkan.”, (Susanti dan Wasiyanti, 2017). 
Terkait dengan latar belakang diatas, penelitian ini bertujuan untuk merancang dan membangun sebuah Sistem Pendukung Keputusan sebagai metode yang dapat memberikan kemudahan dan efektifitas dalam pengolahan data dalam menentukan keputusan sehingga dapat membantu dalam memberikan keputusan dengan hasil yang maksimal.

\section{METODE}

1. Tahapan Penelitian

Tahapan tahapan penelitian mencakup langkah-kangkah dalam pelaksanaan penelitian dari awal sampai akhir. Masing-masing langkah tersebut bisa dilihat pada gambar 1, sebagai berikut:

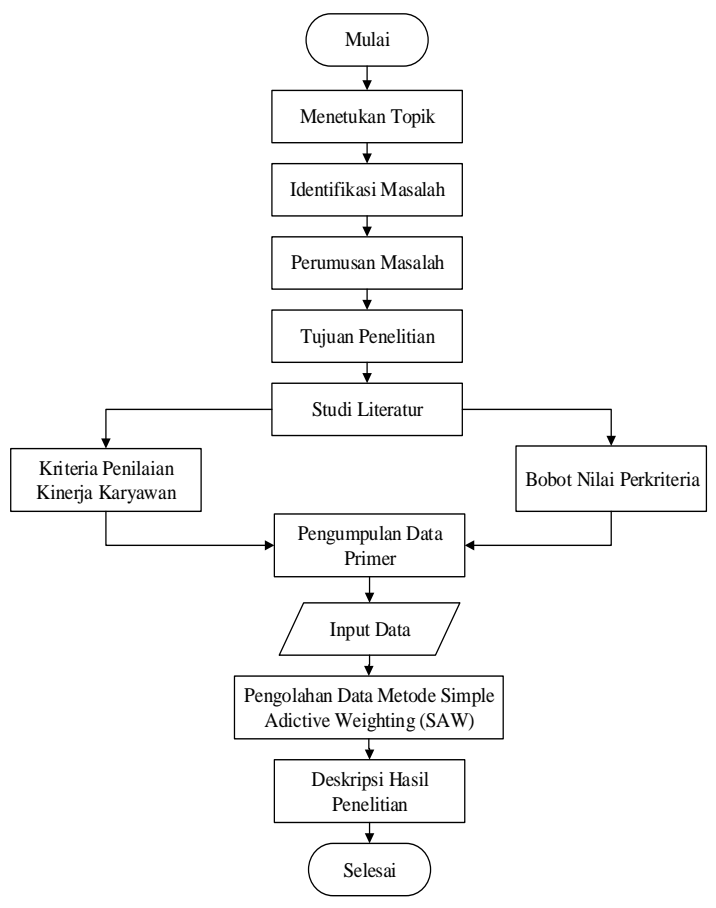

Gambar 1. Tahapan Penelitian a. Menetukan topik

Pada tahap awal ini akan menentukan topik akan digunakan penulis dalam melakukan penelitian.

b. Identifikasi masalah

Mengidentifikasi masalah yang akan dibahas pada penelitian, yang berkaitan dengan penilaian kinerja karyawan berdasarkan literatur dan informasi yangtelah diperoleh.

c. Perumusan masalah

Mendefinisikan proses kinerja karyawan yang ada, serta meumuskan masalah sesuai dengan batasan ruang lingkup yang akan diteliti.

d. Tujuan penelitian

Menentukan tujuan yang akan dicapai dari perumusan masalah yang terjadi di penelitian ini yang bertujuan untuk mengelola data penilaian kinerja karyawan dengan menggunakan metode Simple Additive Weighting (SAW).

e. Studi literatur

Mempelajai literature yang akan digunakan sebagai kajian teori dengan permasalahan yang sama dalam penelitian yang terkait dengan penilaian kinerja karyawan, serta dapat menentukan bobot nilai perkriteria. 
f. Pengumpulan data primer

Untuk menetukan kriteria yang digunakan sebagai variabel penilaian. Mengumpulkan data berdasarkan kuesioner yang telah diisi bobot nilai oleh responden sesuai dengan kriteria yang telah ditentukan.

g. Input data

Data kuesioner yang telah diisi oleh responden akan diinput datanya.

h. Pengilahan data

$\begin{aligned} & \text { Pemberian kode } \\ & \text { pengolahan data }\end{aligned}$
$\begin{aligned} & \text { dengan } \\ & \text { menggunakan metode }\end{aligned}$
Adictive Weimple
sehingga dapat diperoleh hasil dan
kesimpulan penelitian yang telah
dilakukan.

2. Instrumen Penelitian

Instrumen adalah alat bantu dalam melakukan penelitian guna mengumpulkan data darri berbagai pihak dengan menggunakan suatu metode. Adapun pengukuran variabel yang digunakan dalam pembuatan kuisioner yaitu menggunakan skala Likert, dengan skala nilai positif antara Sangat Rendah (SR), Rendah (R), Cukup (C), Tinggi (T), dan Sangat Tinggi (ST). Berikut ini variabel-variabel penelitian yang digunakan sebagai pertanyaan

kuisioner, dapat dilihat dalam tabel 1:

Tabel 1.Instrumen Penelitian

\begin{tabular}{|c|c|}
\hline Variabel & Pertanyaan \\
\hline \multirow[t]{2}{*}{ Integritas } & $\begin{array}{l}\text { Taat terhadap semua } \\
\text { aturan dan prosedur } \\
\text { yang ditetapkan atasan }\end{array}$ \\
\hline & $\begin{array}{l}\text { Menjalankan pekerjaan } \\
\text { sesuai prosedur }\end{array}$ \\
\hline \multirow[t]{2}{*}{ Kerja Sama } & $\begin{array}{l}\text { Mampu bekerja sama } \\
\text { dengan rekan kerja dan } \\
\text { atasan }\end{array}$ \\
\hline & $\begin{array}{l}\text { Adanya saling percaya } \\
\text { terhadap rekan kerja }\end{array}$ \\
\hline Komunikasi & $\begin{array}{l}\text { Kemampuan } \\
\text { komunikasi yang baik } \\
\text { dan benar }\end{array}$ \\
\hline \multirow{2}{*}{ Kualitas Kerja } & $\begin{array}{l}\text { Pencapaian kerja dapat } \\
\text { memenuhi target }\end{array}$ \\
\hline & $\begin{array}{l}\text { Memiliki sikap yang } \\
\text { baik }\end{array}$ \\
\hline \multirow{3}{*}{ Disiplin Kerja } & $\begin{array}{l}\text { Tidak pernah absen } \\
\text { tanpa alasan yang jelas }\end{array}$ \\
\hline & $\begin{array}{l}\text { Memiliki sikap yang } \\
\text { baik }\end{array}$ \\
\hline & $\begin{array}{l}\text { Menjalankan pekerjaan } \\
\text { sesuai prosedur }\end{array}$ \\
\hline
\end{tabular}

Sumber : Hasil Penelitian (2019)

3. Metode Analisis Data

Metode penelitian yang digunakan ialah metode Simple Additive Weighting $(S A W)$. Adapun langkahlangkah penyelesaian metode Simple Additive Weighting (SAW) adalah sebagai berikut:

a. Menentukan kriteria-kriteria yang akan dijadikan acuan dalam pengambilan keputusan, yaitu $\mathrm{Ci}$. 
b. Memberikan rating kecocokan setiap alternatif pada setiap kriteria.

c. Membuat matriks keputusan berdasarkan kriteria (Ci), kemudian melakukan normalisasi matriks berdasarkan persamaan yang sesuai dengan jenis atribut sehingga diperoleh matriks ternormalisasi R.

d. Hasil akhir dari setiap proses perangkingan yaitu penjumlahan dari perkalian matriks ternormalisasi $\mathrm{R}$ dengan vector bobot sehingga diperoleh nilai terbesar yang dipilih sebagai aternatif terbaik (Ai) sebagai solusi.

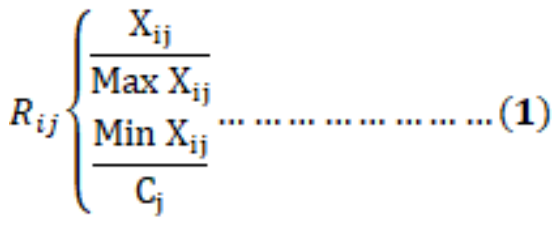

Keterangan:

$$
\begin{aligned}
\mathrm{R}_{\mathrm{ij}}= & \text { Nilai rating kinerja } \\
& \text { ternormalisasi } \\
\mathrm{X}_{\mathrm{ij}} & \text { Nilai atribut yang } \\
& \text { dimiliki dari setiap } \\
& \text { kriteria. } \\
\text { Max } \mathrm{X}_{\mathrm{ij}}= & \text { Nilai terbesar dari } \\
& \text { setiap kriteria } \\
\text { Min } \mathrm{X}_{\mathrm{ij}}= & \text { Nilai terkecil dari } \\
\text { Benefit }= & \text { setiap kriteria } \\
\text { Cost } & \text { ada nilai terbesar } \\
& = \\
& \text { Jika nilah ilai terbaik } \\
& \text { adalah nilai terbaik }
\end{aligned}
$$

e. Hasil akhir pregerensi (Vi) diperoleh dari penjumlahan dari perkalian elemen baris matriks ternormalisasi
(R) dengan bobot preferensi (W) yang bersesuaian dengan elemen kolom matriks (R) ternormalisasi dalam suatu baris sesuai dengan solusi alternatif pilihan yang diberikan

$$
V i=\sum_{W j R i j}^{N} \ldots \ldots \ldots \ldots \ldots
$$

Nilai Vi yang lebih besar mengindikasikan bahwa alternatif $\mathrm{Ai}$ lebih terpilih.

\section{Keterangan:}

$\begin{aligned} \mathrm{Vi} & =\text { Nilai akhir dari } \\ & =\begin{array}{l}\text { alternatif } \\ \mathrm{Wj}\end{array} \quad \begin{array}{l}\text { ditentukan } \\ \text { Rij }\end{array} \quad \text { Normalisasi Matriks }\end{aligned}$

\section{HASIL DAN PEMBAHASAN}

1. Data Riset.

Berdasarkan data yang diperoleh dari PT. Kereta Commuter Indonesia tahun 2019, maka dapat diperoleh data calon karyawan seleksi untuk selanjutnya di konversi kedalam nilai bobot. Data yang ditampilkan ini sebanyak 11 data calon karyawan. Data didapatkan dari hasil pengisian kuesioner oleh responden. Untuk meghitung hasil kuesioner digunakan alternatif jawaban dengan menggunakan skala likert dengan 5 skala yaitu, sangat tidak puas, cukup 
puas, puas, dan puas, (Sugiyono, 2012). Begitu pula dengan kuesioner ekspetasi yang menggunakan skala likert yaitu, sangat tidak penting, tidak penting,cukup penting, penting dan sangat penting.

2. Pengolahan Data Menggunakan metode Simple Additive Weighting $(S A W)$. Setelah data calon karyawan diperoleh, selanjutnya adalah menentukan kriteria-kriteria sebagai acuan dalam pengambilan keputusan untuk karyawan berprestasi berdasarkan kuesioner yang disebar kepada 11 karyawan PT. Kereta Commuter Indonesia Stasiun Rawa Buntu, data yang diperoleh sebagai berikut:

Tabel 2. Hasil Penilaian

\begin{tabular}{|c|c|c|c|c|c|}
\hline 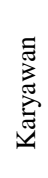 & 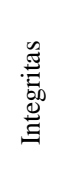 & 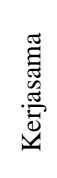 & 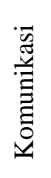 & 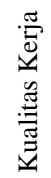 & 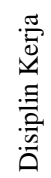 \\
\hline 1 & 9 & 10 & 5 & 9 & 13 \\
\hline 2 & 9 & 9 & 4 & 8 & 13 \\
\hline 3 & 9 & 10 & 5 & 9 & 13 \\
\hline 4 & 9 & 9 & 5 & 9 & 12 \\
\hline 5 & 9 & 9 & 5 & 9 & 12 \\
\hline 6 & 10 & 10 & 5 & 9 & 13 \\
\hline 7 & 8 & 10 & 5 & 8 & 12 \\
\hline 8 & 8 & 9 & 4 & 9 & 13 \\
\hline 9 & 9 & 10 & 5 & 10 & 12 \\
\hline 10 & 9 & 9 & 4 & 9 & 15 \\
\hline 11 & 9 & 9 & 5 & 9 & 13 \\
\hline
\end{tabular}

Sumber: Hasil Penelitian (2019)
Menentukan kriteria - kriteria yang akan dijadikan acuan dalam pengambilan keputusan, yaitu $\mathrm{Cj}$. Langkah kedua memberikan nilai setiap alternatif $\mathrm{Ai}$ pada setiap kriteria yang sudah ditentukan, dimana nilai tersebut diperoleh berdasarkan nilai crisp; I - 1, 2, ..... , $m$ dan $\mathrm{j}=1,1, \ldots$

a. Kriteria Integritas

Kriteria integritas diambil dari bagaimana karyawan mentaati peraturan yang telah dibuat oleh perusahaan. Kriteria dapat dilihat pada tabel 3 berikut:

Tabel 3. Kriteria Integritas

\begin{tabular}{|c|c|c|}
\hline $\begin{array}{c}\text { Kualitas } \\
\text { Kerja (C1) }\end{array}$ & Variabel & $\begin{array}{c}\text { Bobot } \\
\text { Kriteria }\end{array}$ \\
\hline 1 & $\begin{array}{c}\text { Sangat } \\
\text { Tidak } \\
\text { Setuju }\end{array}$ & 0 \\
\hline 2 & $\begin{array}{c}\text { Tidak } \\
\text { Setuju }\end{array}$ & 0,25 \\
\hline 3 & $\begin{array}{c}\text { Kurang } \\
\text { Setuju }\end{array}$ & 0,5 \\
\hline 4 & Setuju & 0,75 \\
\hline 5 & $\begin{array}{c}\text { Sangat } \\
\text { Setuju }\end{array}$ & 1 \\
\hline
\end{tabular}

Sumber: Hasil Penelitian (2019)

b. Kriteria Kerja Sama

Kriteria kerja sama diambil dari bagaimana karyawan bisa bekerja sama terhadap karyawan lainnya. 
Kriteria dapat dilihat pada tabel 4 berikut:

Tabel 4. Kriteria Kerja Sama

\begin{tabular}{|c|c|c|}
\hline $\begin{array}{c}\text { Kualitas } \\
\text { Kerja (C1) }\end{array}$ & Variabel & $\begin{array}{c}\text { Bobot } \\
\text { Kriteria }\end{array}$ \\
\hline 1 & $\begin{array}{c}\text { Sangat } \\
\text { Tidak } \\
\text { Setuju }\end{array}$ & 0 \\
\hline 2 & $\begin{array}{c}\text { Tidak } \\
\text { Setuju }\end{array}$ & 0,25 \\
\hline 3 & $\begin{array}{c}\text { Kurang } \\
\text { Setuju }\end{array}$ & 0,5 \\
\hline 4 & Setuju & 0,75 \\
\hline 5 & $\begin{array}{c}\text { Sangat } \\
\text { Setuju }\end{array}$ & 1 \\
\hline
\end{tabular}

Sumber: Hasil Penelitian (2019)

c. Kriteria Komunikasi

Kriteria komunikasi diambil dari bagaimana karyawan bisa menjalin komunikasi antara rekan kerja dan pimpinannya. Kriteria dapat dilihat pada tabel 5 berikut:

Tabel 5. Kriteria Komunikasi

\begin{tabular}{|c|c|c|}
\hline $\begin{array}{c}\text { Kualitas } \\
\text { Kerja }(\mathrm{C} 1)\end{array}$ & Variabel & $\begin{array}{c}\text { Bobot } \\
\text { Kriteria }\end{array}$ \\
\hline 1 & $\begin{array}{c}\text { Sangat } \\
\text { Tidak } \\
\text { Setuju }\end{array}$ & 0 \\
\hline 2 & $\begin{array}{c}\text { Tidak } \\
\text { Setuju }\end{array}$ & 0,25 \\
\hline 3 & $\begin{array}{c}\text { Kurang } \\
\text { Setuju }\end{array}$ & 0,5 \\
\hline 4 & Setuju & 0,75 \\
\hline 5 & $\begin{array}{c}\text { Sangat } \\
\text { Setuju }\end{array}$ & 1 \\
\hline
\end{tabular}

Sumber: Hasil Penelitian (2019)

d. Kriteria Kualitas Kerja

Kriteria kualitas kerja diambil dari bagaimana karyawan dapat menyelesaikan pekerjaan secara tepat dan cepat. Kriteria dapat dilihat pada tabel 6 berikut:

Tabel 6. Kriteria Kualitas Kerja

\begin{tabular}{|c|c|c|}
\hline $\begin{array}{c}\text { Kualitas } \\
\text { Kerja }(\mathrm{C} 1)\end{array}$ & Variabel & $\begin{array}{c}\text { Bobot } \\
\text { Kriteria }\end{array}$ \\
\hline 1 & $\begin{array}{c}\text { Sangat } \\
\text { Tidak } \\
\text { Setuju }\end{array}$ & 0 \\
\hline 2 & $\begin{array}{c}\text { Tidak } \\
\text { Setuju }\end{array}$ & 0,25 \\
\hline 3 & $\begin{array}{c}\text { Kurang } \\
\text { Setuju }\end{array}$ & 0,5 \\
\hline 4 & Setuju & 0,75 \\
\hline 5 & $\begin{array}{c}\text { Sangat } \\
\text { Setuju }\end{array}$ & 1 \\
\hline
\end{tabular}

Sumber: Hasil Penelitian (2019)

e. Kriteria Disiplin Kerja

Kriteria disiplin kerja diambil dari bagaimana karyawan dalam mentaati peraturan disiplin kerja. Kriteria dapat dilihat pada tabel 7 berikut:

Tabel 7. Kriteria Disiplin Kerja

\begin{tabular}{|c|c|c|}
\hline $\begin{array}{c}\text { Kualitas } \\
\text { Kerja }(\mathrm{C} 1)\end{array}$ & Variabel & $\begin{array}{c}\text { Bobot } \\
\text { Kriteria }\end{array}$ \\
\hline 1 & $\begin{array}{c}\text { Sangat } \\
\text { Tidak } \\
\text { Setuju }\end{array}$ & 0 \\
\hline 2 & $\begin{array}{c}\text { Tidak } \\
\text { Setuju }\end{array}$ & 0,25 \\
\hline 3 & $\begin{array}{c}\text { Kurang } \\
\text { Setuju }\end{array}$ & 0,5 \\
\hline 4 & Setuju & 0,75 \\
\hline 5 & $\begin{array}{c}\text { Sangat } \\
\text { Setuju }\end{array}$ & 1 \\
\hline
\end{tabular}

Sumber: Hasil Penelitian (2019) 
Setelah didapatkan kriteria yang akan dijadikan sebagai acuan penilaian karyawan berprestasi selanjutnya melakukan normalisasi matriks berdasarkan persamaan yang disesuaikan dengan jenis atribut (atribut keuntungan ataupun atribut biaya) sehingga diperoleh matriks ternormalisasi R. Hasil matriks ternormaliasi adalah sebagai berikut :

Tabel 8. Normalisasi data

\begin{tabular}{|c|c|c|c|c|c|}
\hline 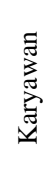 & 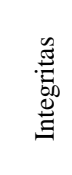 & 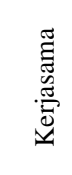 & 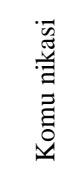 & 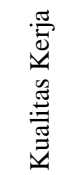 & 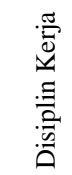 \\
\hline 1 & 0.88 & 1.00 & 0.75 & 0.88 & 0.83 \\
\hline 2 & 0.88 & 0.88 & 1.00 & 0.75 & 0.83 \\
\hline 3 & 0.88 & 1.00 & 1.00 & 0.88 & 0.83 \\
\hline 4 & 0.88 & 0.88 & 1.00 & 0.88 & 0.75 \\
\hline 5 & 0.88 & 0.88 & 1.00 & 0.88 & 0.75 \\
\hline 6 & 1.00 & 1.00 & 1.00 & 0.88 & 0.83 \\
\hline 7 & 0.75 & 1.00 & 1.00 & 0.75 & 0.75 \\
\hline 8 & 0.75 & 0.88 & 0.75 & 0.88 & 0.83 \\
\hline 9 & 0.88 & 1.00 & 1.00 & 1.00 & 0.75 \\
\hline 10 & 0.88 & 0.88 & 0.75 & 0.88 & 1.00 \\
\hline 11 & 0.88 & 0.88 & 1.00 & 0.88 & 0.83 \\
\hline
\end{tabular}

Sumber: Hasil Penelitian (2019)

Tabel 8 adalah data dari setiap kriteria dibagikan dengan nilai maksimum dari maisng-masing kriteria sehingga diperoleh nilai yang sesuai pada tabel 8 . Sehingga diperoleh nilai sebagai berikut:

$$
\mathrm{X}=\begin{array}{ccccc}
0,88 & 1 & 0,75 & 0,88 & 0,83 \\
0,88 & 0,88 & 1 & 0,75 & 0,83 \\
0,88 & 1 & 1 & 0,88 & 0,83 \\
0,88 & 0,88 & 1 & 0,88 & 0,75
\end{array}
$$

$\begin{array}{ccccc}0,88 & 0,88 & 1 & 0,88 & 0,75 \\ 1 & 1 & 1 & 0,88 & 0,83 \\ 0,75 & 1 & 1 & 0,75 & 0,75 \\ 0,75 & 0,88 & 0,75 & 0,88 & 0,83 \\ 0,88 & 1 & 1 & 1 & 0,75 \\ 0,88 & 0,88 & 0,75 & 0,88 & 1 \\ 0,88 & 0,88 & 1 & 0,88 & 0,83\end{array}$

3. Proses Pemeringkatan

Berikut ini merupakan perhitungan nilai preferensi dari setiap alternatif yang telah ditentukan. Proses perangkingan dengan menggunakan bobot yang telah diberikan oleh pengambil keputusan, proses perhitungan dapat dilihat pada tabel 9

\begin{tabular}{|c|c|c|}
\hline Vector & \multicolumn{2}{|c|}{ Proses Perhitungan } \\
\hline V1 & : & $\begin{array}{l}(0,2 \times 0,88)+(0,2 \times 1)+(0,1 \times 0,75) \\
+(0,2 \times 0,88)+(0,3 \times 0,83)=0,876\end{array}$ \\
\hline $\mathrm{V} 2$ & : & $\begin{array}{l}(0,2 \times 0,88)+(0,2 \times 0,88)+(0,1 \times 1) \\
+(0,2 \times 0,75)+(0,3 \times 0,83)=0,851\end{array}$ \\
\hline V3 & : & $\begin{array}{l}(0,2 \times 0,88)+(0,2 \times 1)+(0,1 \times 1)+ \\
(0,2 \times 0,88)+(0,3 \times 0,83)=0,901\end{array}$ \\
\hline V4 & $:$ & $\begin{array}{l}(0,2 \times 0,88)+(0,2 \times 0,88)+(0,1 \times 1) \\
+(0,2 \times 0,88)+(0,3 \times 0,75)=0,853\end{array}$ \\
\hline V5 & $:$ & $\begin{array}{l}(0,2 \times 0,88)+(0,2 \times 0,88)+(0,1 \times 1) \\
+(0,2 \times 0,88)+(0,3 \times 0,75)=0,853\end{array}$ \\
\hline V6 & $:$ & $\begin{array}{l}(0,2 \times 1)+(0,2 \times 1)+(0,1 \times 1)+ \\
(0,2 \times 0,88)+(0,3 \times 0,75)=0,901\end{array}$ \\
\hline V7 & $:$ & $\begin{array}{l}(0,2 \times 0,75+(0,2 \times 1)+(0,1 \times 1)+ \\
(0,2 \times 0,75)+(0,3 \times 0,75)=0,825\end{array}$ \\
\hline V8 & : & $\begin{array}{l}(0,2 \times 0,75)+(0,2 \times 0,88)+(0,1 \times \\
0,75)+(0,2 \times 0,88)+(0,3 \times 0,83)= \\
0,826\end{array}$ \\
\hline V9 & : & $\begin{array}{l}(0,2 \times 0,88)+(0,2 \times 1)+(0,1 \times 1)+ \\
(0,2 \times 1)+(0,3 \times 0,75)=0,910\end{array}$ \\
\hline V10 & : & $\begin{array}{l}(0,2 \times 0,88)+(0,2 \times 0,88)+(0,1 \times \\
0,75)+(0,2 \times 0,75)+(0,3 \times 1)= \\
0,877\end{array}$ \\
\hline V11 & : & $\begin{array}{l}(0,2 \times 0,88)+(0,2 \times 0,88)+(0,1 \times 1) \\
+(0,2 \times 0,88)+(0,3 \times 0,83)=0,877\end{array}$ \\
\hline
\end{tabular}
berikut:

Tabel 9. Perhitungan Pemeringkatan

Sumber: Hasil Penelitian (2019)

Vektor bobot: $\mathrm{W}=\left(\begin{array}{lllll}2 & 2 & 1 & 2 & 3\end{array}\right)$ sehingga diperoleh perkalian dari nilai normaliasi dengan vector bobot yang 
sudah ditentukan. Hasil perkalian matrik normalisasi nilai dengan vector bobot seperti pada tabel 10 berikut:

Tabel 10. Perkalian nilai normalisasi dengan vector bobot

\begin{tabular}{|c|c|c|c|c|c|c|}
\hline 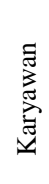 & $\begin{array}{l}\stackrel{\mathscr{G}}{G} \\
\text { D. } \\
\stackrel{\Xi}{\Xi}\end{array}$ & 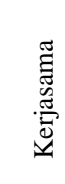 & 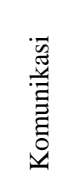 & 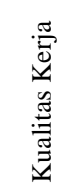 & 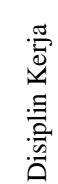 & $>$ \\
\hline 1 & 0.75 & 0.75 & 0.75 & 0.88 & 0.83 & 0.80 \\
\hline 2 & 0.75 & 1.00 & 1.00 & 1.00 & 0.92 & 0.93 \\
\hline 3 & 0.75 & 1.00 & 1.00 & 0.88 & 0.92 & 0.90 \\
\hline 4 & 0.75 & 0.88 & 0.75 & 0.75 & 0.83 & 0.80 \\
\hline 5 & 0.88 & 0.88 & 1.00 & 0.75 & 0.75 & 0.83 \\
\hline 6 & 0.75 & 0.88 & 0.75 & 0.75 & 0.92 & 0.83 \\
\hline 7 & 1.00 & 1.00 & 1.00 & 0.88 & 1.00 & 0.98 \\
\hline 8 & 0.75 & 0.75 & 0.75 & 0.88 & 0.92 & 0.83 \\
\hline 9 & 0.75 & 0.88 & 1.00 & 0.88 & 0.75 & 0.83 \\
\hline 10 & 0.88 & 1.00 & 0.75 & 0.75 & 0.67 & 0.80 \\
\hline 11 & 0.88 & 1.00 & 1.00 & 0.75 & 0.83 & 0.88 \\
\hline
\end{tabular}

Sumber : Hasil Penelitian (2019)

Hasil akhir diperoleh dari proses perankingan yaitu penjumlahan dari perkalian matriks ternormalisasi $\mathrm{R}$ dengan vektor bobot sehingga diperoleh nilai terbesar yang dipilih sebagai alternatif terbaik (Ai) sebagai solusi, berdasarkan tabel 3 dapat diperoleh kesimpulan bahwa nilai diatas bahwa Maman Saryudin yang menjadi karyawan berprestasi di PT. Kereta Commuter Indonesia Stasiun Rawa Buntu.

Berdasarkan hasil dan pembahasan yang telah dijelaskan sebelumnya, maka dapat ditarik kesimpulan berikut:

1. Pemberian kriteria-kriteria dalam penentuan penilaian kinerja karyawan dapat membantu dalam mengambil keputusan untuk menentukan kinerja karyawan berprestasi.

2. Dengan menerapkan metode Simple Additive Weighting (SAW) proses pemilihan kinerja karyawan lebih efesien sehingga pihak stasiun lebih cepat memutuskan karyawan yang berprestasi.

3. Sistem pengambilan keputusan dengan metode Simple Additive Weighting (SAW) telah membantu pihak staisun dalam menentukan pemilihan kinerja karyawan yang berprestasi.

Adapun untuk pengembangan penelitian selanjutnya, penelitian ini dapat dikembangkan dengan menambahkan beberapa variabel sesuai dengan referensi terkait. Penelitian ini juga dapat dikembangkan pada metode selain Simple Additive Weighting.

\section{DAFTAR PUSTAKA}

Agustini, F. and Ariska, E. R. (2019) 'Penerapan Metode Simple Additive Weighting (SAW) Dengan Model Fuzzy Model Atribute Decision Making (FMADM) Penilaian Kinerja Karyawan DTpeduli Bekasi', TECHNO Nusa Mandiri, 16(1), 
pp. 21-28.

Chyntiari, Y. E. and Prihatin, T. (2018) 'Implementasi Metode Simple Additive Weighting Untuk Pemilihan Guru Berprestasi Pada SMP Islam Pondok Duta', Jurnal Ilmu Pengetahuan Dan Teknologi Komputer, 3(2), pp. 233-238.

Hi Lawu, S., Nelfianti, F. and Khoirunnada, M. (2019) 'Pengaruh Disiplin Kerja Terhadap Prestasi Kerja Karyawan Pada Sdi AlAzhar 19', Mabiska, 4(1), pp. 8187.

Ilham, M. and Bakhri, S. (2017) 'Pemilihan Karyawan Terbaik Di PT. Sehat Bahagia Keluarga Dengan Metode Simple Additive Weighting (SAW)', Paradigma, 19(2), pp. 108-112.

Safitri, K., Waruwu, F. T. and Mesran (2017) 'Sistem Pendukung Keputusan Pemilihan Karyawan Berprestasi Dengan Menggunakan Metode Analytical Hieararchy Process ( Studi Kasus: PT. Capella Dinamik Nusantara Takengon )', Media Informatika Budidarma, 1(1), pp. 17-21.

Sugiyono (2012) Metode Penelitian Kuantitatif Kualitatif dan $R \& D$. Bandung: Alfabeta.

Susanti, M. I. and Wasiyanti, S. (2017) 'Metode Simple Additive Weighting ( Saw ) Dalam Penentuan Pemberian Beasiswa Pada Siswa Sekolah Menengah Atas', Swabumi, 5(2), pp. 114123. 